\title{
Servicios de hemodiálisis por la seguridad del paciente. Implantación de un sistema de gestión de riesgos
}

\author{
Lucía Ma García Rivela, María Ana Rey Martínez, Mónica Rodríguez Castaño, María Bello Vilar, Diana León \\ Requeijo, Marta Castro Castro
}

\section{Hospital da Barbanza. A Coruña}

\section{Introducción:}

La seguridad es una de las dimensiones de la calidad más valorada actualmente en las organizaciones sanitarias, como prueba, su incorporación en los objetivos estratégicos de los distintos servicios de salud. Entre éstos, se encuentran la implantación de sistemas de gestión de riesgos asistenciales. Todo estalló con el demoledor informe "To err is human", en el que se calculaban entre 44.000 y 98.000 muertes anuales relacionadas con errores durante la asistencia sanitaria en los hospitales estadounidenses. Ello puso en evidencia la escasa seguridad en los procesos asistenciales. En nuestro ámbito, el estudio ENEAS (Estudio nacional de eventos adversos ligados a la hospitalización) en 2006, concluye que un $8,9 \%$ de los pacientes que ingresan en nuestros hospitales sufre algún evento adverso. Los servicios de hemodiálisis no están exentos de riesgos asociados al tratamiento dialítico.

\section{Objetivos:}

- Proporcionar una asistencia más segura en el Servicio de Hemodiálisis (HD) de un Hospital Comarcal.

- Crear cultura de seguridad de pacientes entre los profesionales.

- Identificar los riesgos reales y potenciales en HD.

- Analizar, evaluar y tratar los riesgos inaceptables o severos.

- Implementar un sistema de Gestión de riesgos según la Norma 179003.

\section{Material y método:}

- Aprobación entre la alta dirección del centro, los profesionales de la unidad del servicio de HD y la responsable de calidad de los objetivos marcados definiéndose la Política de Gestión de Riesgos.

- Formación de los profesionales, responsable de calidad y dirección en Seguridad del paciente.

- Elaboración del plan de implantación.

- Constitución del GIAR (Grupo de Identificación y Análisis de Riesgos) del que forma parte todo el personal del HD.

- Establecimiento de los criterios de análisis (Gravedad, Probabilidad y Capacidad de no detección).

- Identificación, análisis y evaluación de los riesgos.

- Elaboración del mapa de riesgos resultante.

- Priorización de los riesgos a tratar. Elaboración e implementación de los planes de tratamiento.

- Definición de los registros de riesgos y del sistema de notificación.

- Confección del soporte documental.

\section{Resultados:}

- Todo el personal participa en la implantación de la norma. 
- Se realizan 8 notificaciones de eventos adversos en el 2011,34 en el 2012 y 11 en el primer trimestre del 2013.

- Se verifica la efectividad de los planes de tratamiento implantados.

- Existe soporte documental del sistema (Manual de Gestión de Riesgos, Procedimiento de Identificación, análisis y evaluación de riesgos, listado de eventos centinela, pseudo-AMFE de los riesgos identificados, mapa de riesgos, etc).

- El Servicio de HD del Hospital Comarcal obtiene la certificación en la Norma 179003 en diciembre de 2011.

\section{Conclusiones:}

- Los registros de los incidentes y eventos adversos objetivan una mejora en la cultura de seguridad de pacientes.

- La participación activa del equipo de trabajo evidencia la factibilidad de la implantación de la Norma y su mantenimiento.
- Se incorpora el criterio "seguridad" en todas las decisiones asistenciales y organizativas.

- El servicio es el primer servicio asistencial en el territorio español en certificarse en la Norma 179003.

\section{Referencias Bibliográficas}

1. Kohn LT, Corrigan J, Donaldson MS, To errr is Human. IOM. Washington, D.C.: National Academy Press; 2000.

2. Estudio ENEAS 2005. Estudio Nacional sobre los Efectos Adversos ligados a la Hospitalización. Madrid: Ministerio de Sanidad y Consumo 2006.

3. Clasificación Internacional para la Seguridad del Paciente (CISP). Enero 2009.

4. Comité técnico AEN/CTN 179 Calidad y seguridad en los centros de asistencia sanitaria-AENOR. Norma UNE 179003. Servicios sanitarios. Gestión de riesgos para la seguridad del paciente. Madrid. AENOR. Junio 2010. 